\title{
Construção de ambiente de ensino de robótica remota: democratizando o desenvolvimento do pensamento computacional em alunos da educação básica
}

\section{Leonardo Costella, Marco Antônio Sandini Trentin, Victor Grando do Amarante, Adriano Canabarro Teixeira.}

Instituto de Ciências Exatas e Geociências - Universidade de Passo Fundo (UPF)

$$
\begin{gathered}
\text { Passo Fundo - RS - Brasil } \\
\text { \{134383, trentin,138736, teixeira\} @upf.br }
\end{gathered}
$$

\begin{abstract}
The computational thinking is nowadays a fundamental hability for everyone, not only for computer scientists. Thus, along with other competences such as reading, writing and arithmetic, it is recommended to include computational thinking as didactic content in basic education. The educational robotics is one of the methodologic resources that gives the possibility to disseminate the computational thinking in a ludic and interactive way. It is believed that this work will help the basic education students to have contact with robotics, favoring the development of computational thinking.
\end{abstract}

Resumo. O pensamento computacional é atualmente uma habilidade fundamental para todos, não somente para cientistas da computação. Dessa forma, juntamente com outras competências como a leitura, escrita e a aritmética, preconiza-se acrescentar o pensamento computacional como conteúdo didático na educação básica. A robótica educacional é um dos recursos metodológicos que possibilitam a disseminação do pensamento computacional de forma lúdica e interativa. Acredita-se que este trabalho auxiliará em oportunizar o contato com a robótica a estudantes da Educação Básica, favorecendo o desenvolvimento do pensamento computacional.

\section{Introdução}

Atrelado diretamente ao estudo e desenvolvimento de mecanismos computacionais, o pensamento computacional foi durante anos tratado como uma habilidade exclusiva de cientistas da computação e mais precisamente de programadores. Somente em 2006, foi apresentado ao mundo a teoria de que essa competência é essencial à todos os seres humanos e que usufruímos da mesma nas mais diversas situações cotidianas (Wing 2006).

Dessa forma, nos últimos anos, vem se discutindo a inserção de disciplinas que visam o desenvolvimento do pensamento computacional em currículos escolares, percebendo a necessidade do aprimoramento por parte dos estudantes de habilidades de aprendizagem criativas e colaborativas, atribuindo lugar às tecnologias oriundas da Ciência da Computação em sala de aula.

É neste cenário e por se tratar de uma tecnologia tangível na busca do pensamento computacional que a robótica educativa, também conhecida como robótica 
pedagógica, vai encontrando espaço, mostrando-se capaz de integrar as tecnologias ao conteúdo pedagógico de forma lúdica e interdisciplinar (Bezerra, 2015).

Atualmente, existem muitos kits de robótica que promovem a robótica educacional e que apresentam diversos recursos pedagógicos, podendo ser aliados a aprendizagem de vários conceitos. Porém, nem todas as escolas possuem condição ou autonomia financeira para que esses kits se tornem habituais dentro das salas de aula.

Nesse sentido, o trabalho apresentado neste artigo tem o objetivo de disponibilizar uma plataforma gratuita e interativa para a aprendizagem de programação para robótica a distância. A plataforma permite que estudante tenha contato com a robótica podendo programar um robô real, sem a necessidade de possuir um aparato robótico ou conhecimentos prévios de eletrônica e mecânica.

Este artigo está organizado da seguinte maneira: o capítulo 2 descreve os conceitos do pensamento computacional e sua disseminação através da robótica educacional; no capítulo 3 são apresentados alguns trabalhos que possuem características semelhantes a esse; no capítulo 4 é demonstrada a metodologia de desenvolvimento do hardware da plataforma; no capítulo 5 são apresentados os resultados provenientes dos testes realizados; e por fim no capítulo 6 são tecidas as considerações finais.

\section{Pensamento computacional e a programação de robôs}

Muitos avanços tecnológicos se deram graças a competição industrial em conjunto com as pesquisas acadêmicas. Desde a concepção da máquina a vapor em 1769 por James Watt, a automação de atividades e processos ganhou proporções importantes, as quais foram intensificadas com o advento dos microchips em 1980 e nos dias atuais com a nanotecnologia e a miniaturização de componentes computacionais.

Diretamente ligada com os objetivos de uma produção automatizada e mais eficiente, a robótica, segundo Bouteille et al. (1997), surgiu com o intuito de realizar os desejos do homem de produzir mais em menos tempo e com menores esforços. E essas características de produção puderam ser adquiridas com a utilização de robôs no auxílio e/ou substituição do trabalho humano em atividades complexas e repetitivas. Cada vez mais pode se observar que a robótica industrial vem ocasionando uma diminuição no número de pessoas envolvidas nos processos produção, bem como um aumento na quantidade de produtos fabricados e ainda, uma melhor utilização de matéria-prima e de energia.

Paralelo aos avanços mercantis, Seymour Papert (1980) vislumbrou o grande poder de atração que a computação e a robótica poderiam proporcionar à educação, agindo como ferramentas potencializadoras no processo de aprendizagem. Essa conjectura deu início aos primeiros estudos a respeito do pensamento computacional.

Essencial no desenvolvimento de aplicações computacionais, o Pensamento Computacional (PC), pode ser classificado segundo Jeannette Wing (2006) como o processo mental que conduz à formulação de problemas e das suas soluções de tal modo que as soluções são representadas numa forma que um agente de processamento de informação é capaz de tratar. 
Dessa forma, é possível constatar que o PC não está vinculado apenas ao desenvolvimento de aplicações computacionais, mas também subsidia aplicabilidades na resolução de problemas do cotidiano que envolvam outras áreas do conhecimento, norteados por conceitos da Ciência da Computação. Ademais, a importância de se desenvolver um pensamento computacional nos dias atuais por vezes pode se comparar com a importância do domínio de outras competências como ler, escrever e calcular.

Valerie Barr e Chris Stephenson (2011, p. 51) afirmam:

The power of computational thinking is that it applies to every other type of reasoning. It enables all kinds of things to get done: quantum physics, advanced biology, human-computer systems, development of useful computational tools."

Neste contexto, a robótica recentemente chegou a escola como um dispositivo potencializador da aprendizagem, possibilitando que situações específicas possam ser criadas a partir do uso de dispositivos robóticos integrados a outros recursos digitais (d'Abreu, 2012).

A Robótica Educativa, também conhecida como robótica pedagógica é caracterizada por ambientes de aprendizagem onde o aluno pode montar e programar um robô ou sistema robotizado. De acordo com Papert et al. (1980), essas atividades permitem que áreas que sempre pareceram muito abstratas passem a serem visualizadas de forma mais clara e tangível pelos estudantes. Zapata, Novales e Guzmán (2004) vão além e colocam a robótica educativa como uma ferramenta que cria ambientes de aprendizagem interessantes e motivadores, colocando o papel do professor como facilitador da aprendizagem e o aluno como construtor ativo.

\section{Trabalhos relacionados}

A seguir serão apresentados alguns trabalhos que possuem algumas características que vão ao encontro deste projeto.

Em 2013, Kulich desenvolveu o SyRoTek- System for robotic e-learning, uma plataforma de desenvolvimento dinâmico, onde os usuários podem desenvolver algoritmos que possibilitem a programação de robôs posicionados em uma arena com alguns objetivos a serem cumpridos. Toda a programação pode ser visualizada por meio de câmeras instaladas na arena. Porém, para testarem suas habilidades na programação de robôs, sem presença física de um dispositivo robótico, é necessária a instalação de ambientes de programação e a utilização de linguagens de baixo nível.

Cruz (2009) concebeu um ambiente para comunicação e controle remote, pela internet do kit de robótica educativa ROBOKIT, onde visava oportunizar a programação à Educação Básica e trazer uma experiência inovadora além de incentivo a programação. O autor conseguiu durante o trabalho dados com resultados expressivos para a formação docente.

\section{Metodologia}

Tendo em vista que a robótica é algo que atrai os estudantes, mas que ao mesmo tempo ainda é incipiente principalmente em escolas públicas que carecem de recursos e não conseguem disponibilizar equipamentos para as atividades educacionais correlatas, visa 
oferecer aos estudantes da Educação Básica a oportunidade de, através da internet, conectar-se a um robô físico e de forma totalmente remota, desenvolver atividades curriculares, bem como, realizar e participar de competições de robótica o que anteriormente era inimaginável devido aos altos custos existentes para aquisição ou confecção de um aparato robótico. Apesar dessa solução apresentar-se intangível, referindo-se ao dispositivo programável, o mesmo permite aos usuários de forma fácil e acessível, o aprimoramento do pensamento computacional.

A plataforma como um todo, é composta de quatro módulos principais: braço robótico e arena, sistema de imagem, plataforma de integração e interface com o usuário. $\mathrm{O}$ usuário deverá desenvolver um programa na interface web e enviar para o servidor que irá interpretar e transmitir os mesmos até o braço robótico.

Na figura 1 é possível observar o delineamento esquemático do projeto, onde o usuário acessa uma interface web, faz sua programação e a submete ao sistema, que analisará os comandos a fim de verificar, por motivos de segurança, se os mesmos não infringem alguns limites existentes no conjunto arena e robô e posteriormente repassar os comandos ao dispositivo robótico. Ao iniciar a execução do programa, o sistema de imagem inicia a captura das imagens e ao final envia uma URL ao usuário para que o mesmo possa conferir se a sua programação atingiu o objetivo previamente proposto.

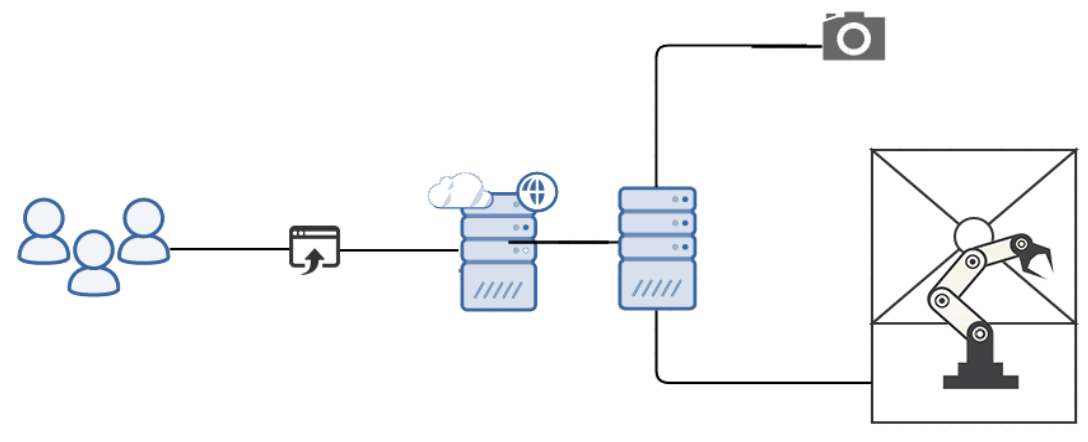

Figura 1. Delineamento esquemático do projeto.

\subsection{Braço Robótico}

A escolha por um braço robótico se deu devido à praticidade que o mesmo proporciona. Por ser um dispositivo de base fixa, o braço é a solução ideal para essa plataforma, a qual necessita que o dispositivo, ao estar disponível, esteja posicionado sempre em sua posição inicial para receber uma nova sequência de comandos, além de não necessitar de um transmissor sem fio na comunicação entre o servidor e o dispositivo robótico. A seguir, são apresentados os materiais e métodos utilizados na confecção do robô.

\subsubsection{Materiais utilizados}

O robô criado para essa pesquisa possui $57 \mathrm{~cm}$ de altura e $46 \mathrm{~cm}$ de alcance em sua extensão máxima. A estrutura do braço robótico é composta de vinte e seis peças, as quais foram em sua totalidade impressas em uma impressora 3D utilizando filamento $100 \%$ PLA. O modelo utilizado foi adaptado de um projeto disponível no repositório 
VI Congresso Brasileiro de Informática na Educação (CBIE 2017)

Anais do XXVIII Simpósio Brasileiro de Informática na Educação (SBIE 2017)

Instructable ${ }^{1}$. Quatro standard servos-motores, dois micro servos-motores, um micro controlador Arduino e uma fonte de alimentação com $5 \mathrm{~V}$ de tensão e $2 \mathrm{~A}$ de corrente, compoem toda a estrutura presente no aparato.

\subsubsection{Programação embarcada}

O firmware embarcado no robô foi desenvolvido na linguagem $C++$. Esse código embarcado é responsável por receber as instruções enviadas pelo usuário via interface web e executá-las no robô, realizando assim os movimentos solicitados.

Dividido em cinco módulos denominados: garra, pulso, cotovelo, ombro e base, o braço recebe da interface web, por intermédio de um servidor, uma sequência de comandos que dita quais módulos movimentar, em qual sequência e qual a quantidade de graus que cada módulo deve mover a cada movimento. A figura 2 demonstra a interação entre interface web, seus comandos e os módulos existentes no aparato robótico.

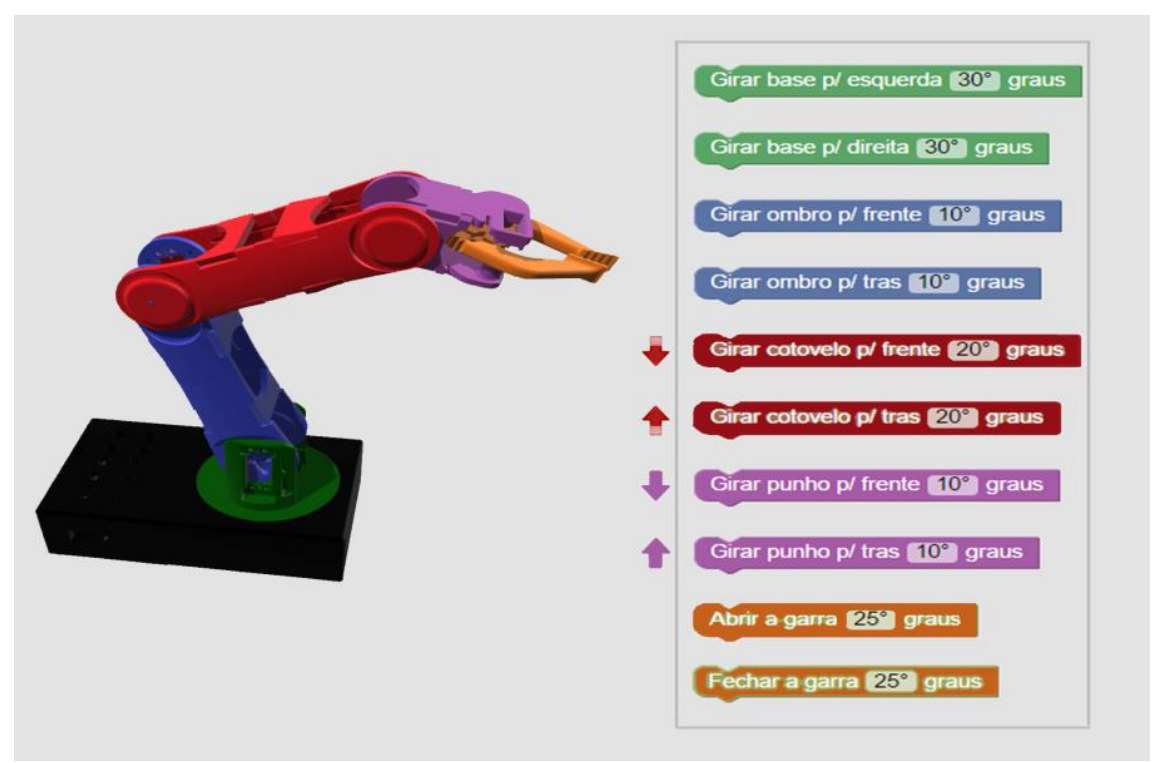

Figura 2. Braço robótico, seus módulos e commandos presentes na interface web.

\subsection{Arena}

Como cenário da plataforma, desenvolveu-se uma arena com $(40$ x 50) $\mathrm{cm}$ de dimensão e em um formato conhecido por duas águas com 4 caimentos. Esse formato permite, graças às elevações laterais, que a bola a ser capturada pelo braço robótico ao final de cada execução permaneça sempre no seu ponto de origem, ou seja, no centro da arena. Dessa forma, a arena, sem nenhum auxílio humano, estará sempre disponível ao próximo usuário que vir a utilizar o aparato robótico.

Dois desafios estão presentes nessa arena: o desafio do basquete e o desafio da argola. No primeiro, o usuário deve desenvolver um código para que o braço robótico

- 1 Projeto disponível sobre a licença creative commons (BY-NC- SA), disponível em http://www.instructables.com/id/3D-Printed-Robot-Arm/ 
VI Congresso Brasileiro de Informática na Educação (CBIE 2017)

Anais do XXVIII Simpósio Brasileiro de Informática na Educação (SBIE 2017)

movimente-se do seu ponto inicial e vá ao encontro da bola, posicionada no centro da arena, e leve a mesma até uma cesta de basquete, que possui $18 \mathrm{~cm}$ de altura, $6,5 \mathrm{~cm}$ de diâmetro, também modelada e impressa na impressora 3D, e que encontra-se ao lado direito do robô no cenário. Semelhante ao desafio do basquete, no desafio da argola o usuário deve novamente codificar no ambiente web uma sequência de códigos para que o braço recolha a bola do seu ponto inicial. Porém, neste, ao invés de acertar a cesta, o usuário para completar o desafio deve fazer com que a bola recolhida pelo robô passe por dentro de um argola, de 7,5 cm de diâmetro, posicionada no seu lado esquerdo. A figura 3 exibe a arena, seus desafios e o robô em atuação.

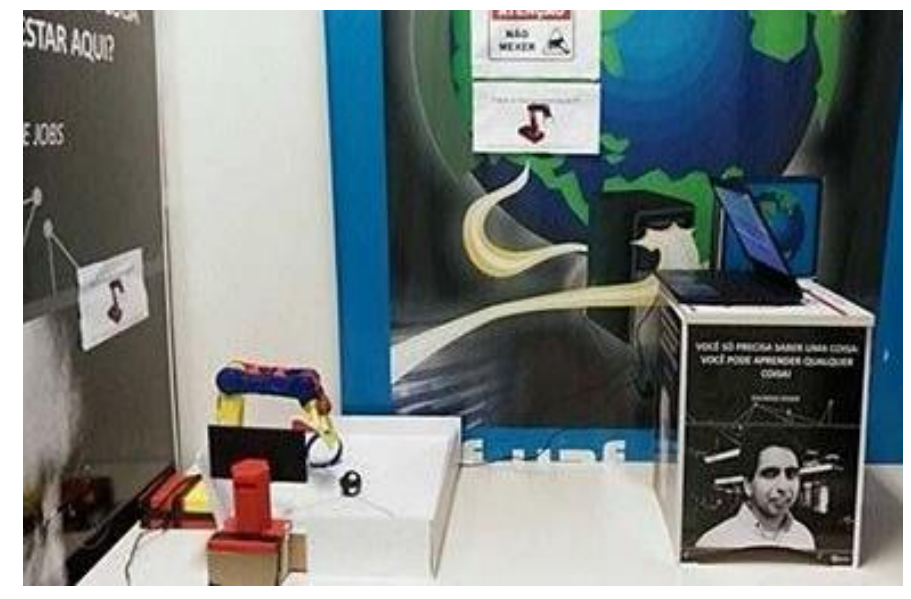

Figura 3. Plataforma em funcionamento.

\subsection{Servidor}

Responsável por coletar os comandos oriundos da interface web e repassar ao robô, o programa servidor fica rodando de forma contínua buscando no banco de dados hospedado na plataforma Firebase ${ }^{2}$ por uma nova sequência de comandos na fila de execuções, retransmitindo os comandos ao robô através da porta serial.

Outra função do servidor é validar a programação recebida, verificando se a mesma está dentro dos limites existentes tanto por parte do robô quando da arena. Essa verificação é de suma importância para aplicação, pois a mesma garante integridade do robô, impedindo que alguma sequência de comandos danifique o mesmo como, por exemplo, forçar um braço do robô a exceder o seu deslocamento para além da arena. Além disso, cabe ao servidor realizar a gravação e transmissão do vídeo para a plataforma web. A gravação se dá por meio de uma webcam conectada a este servidor.

\subsection{Interface web}

Semelhante ao software scratch $^{3}$, a programação do robô também utiliza o conceitos de blocos para a construção da sequência de comandos. Logo, cada bloco possui uma função relacionada aos movimentos que o braço robótico deve executar, bem como,

2 Plataforma móvel para desenvolvimento de aplicativos. Link da plataforma de robótica: https://plataforma-robotica-7d010.firebaseapp.com/

3 Scratch is a free programming language and online community where you can create your own interactive stories, games, and animations: https://scratch.mit.edu/ 
VI Congresso Brasileiro de Informática na Educação (CBIE 2017)

Anais do XXVIII Simpósio Brasileiro de Informática na Educação (SBIE 2017)

qual o deslocamento (em graus) que será realizado neste movimento. A figura 4 exibe a tela principal da aplicação web. Abaixo, é detalhada a funconalidade de cada tela presente na interface web:

- Login: A tela de Login, utiliza a autenticação e identificação dos usuários por meio de uma conta no Facebook ou Google, o que facilita o acesso do mesmo que não necessita realizar um cadastro prévio.

- Programação: A tela de programação é a tela onde o usuário é direcionado, após realizar o login. Nela, o mesmo cria sua sequência de comandos e envia para ser executada pelo robô. Os blocos foram desenvolvidos com a ferramenta Google Blockly Além disso, nesta tela está contida instruções ao usuário, informações referentes a Arena e aos desafios e um questionário facultativo, utilizado como feedback do trabalho.

- Histórico: Nessa tela, o usuário pode visualizer os vídeos referentes as suas últimas programações, além de informações referentes à validação e execução dessas programações. Os vídeos foram hospedados na plataforma S3 da Amazon.

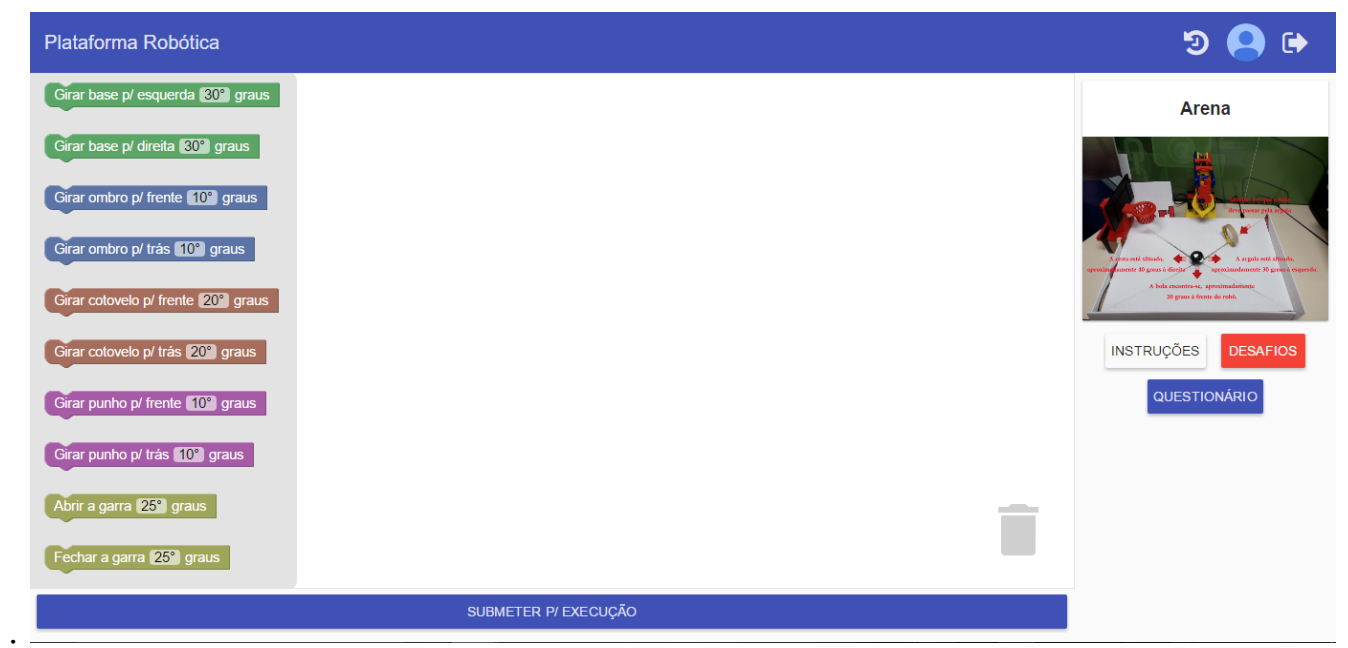

Figura 4. Interface web.

\section{Testes e resultados}

Como forma de validação do trabalho desenvolvido, optou-se pela realização de alguns testes práticos. $\mathrm{O}$ endereço web do sistema foi divulgado em uma rede social e o braço robótico ficou disponível durante três dias. Nesse período, a plataforma para prática de robótica a distância recebeu 219 programas provenientes de 47 usuários cadastrados, totalizando em média 4,7 execuções por usuário.

Além disso, com o intuito de obter um feedback dos usuários que realizaram os testes, disponibilizou-se na interface web da aplicação um questionário facultativo contendo oito perguntas. Esse questionário foi respondido por 14 usuários. As perguntas bem como um resumo das respostas podem ser visualizadas nas figuras 5, 6 e 7 .

A questão dois, com gráfico presente na figura 5, demonstra que apenas 50\% dos usuários que responderam o questionário, não haviam tido até então algum contato com programação. Considerando esse dado, podemos verificar que a programação de 
VI Congresso Brasileiro de Informática na Educação (CBIE 2017)

Anais do XXVIII Simpósio Brasileiro de Informática na Educação (SBIE 2017)

computadores na busca do desenvolvimento do pensamento computacional, ainda é um tema que precisa ganhar força e se tornar mais presente no nosso cotidiano.

\section{1-Escolaridade}

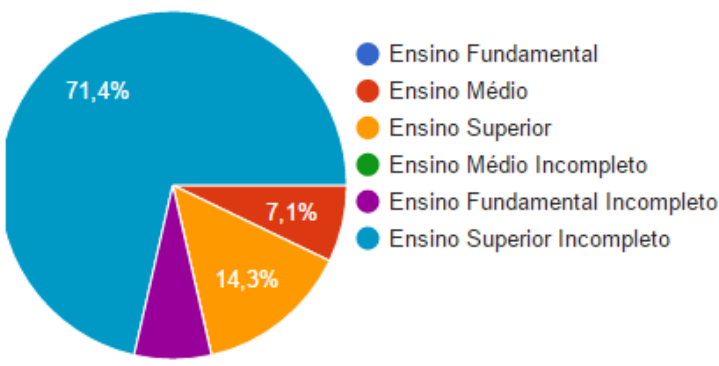

2- Havia tido algum contato com programação antes de utilizar a plataforma de robótica?

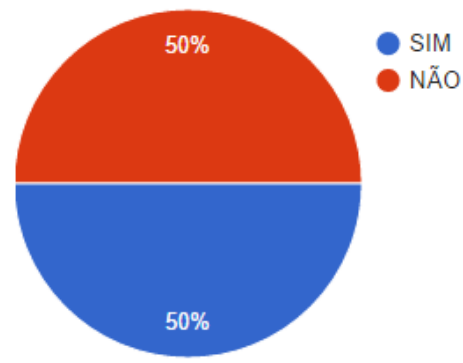

Figura 5. Questões 1 e 2.

$\mathrm{Na}$ questão 4, vide figura 6, quando respondido que sim, uma nova pergunta surgia, questionando o usuário para que o mesmo informasse quais foram as dificuldades encontradas. Seguem as principais elencadas pelos usuários: Dificuldade inicial de entender as direções, antes de enviar o primeiro código, se eram na visão da câmera ou levando em consideração o braço; Dificuldades em usar a plataforma pelo smartphone; Dificil percepção do quão longe a bola está do braço; Os limites dos módulos do braço não ficaram claros, foi necessário enviar um código para entendêlos. Algumas dessas dificuldades se deram devido à não observação dos usuários, as instruções contidas no front-end e que também foram passadas aos mesmos no convite para usar a plataforma. Porém, a grande maioria das dificuldades apontadas foi de suma importância para futuras melhorias a serem realizadas na plataforma.

\section{3-Grau de satisfação (de 1 a 5, 4-Encontrou alguma dificuldade sendo 1 totalmente insatisfeito no desenvolvimento dos desafios e 5 totalmente satisfeito) (14 respostas) presentes na plataforma? \\ (14 respostas)}

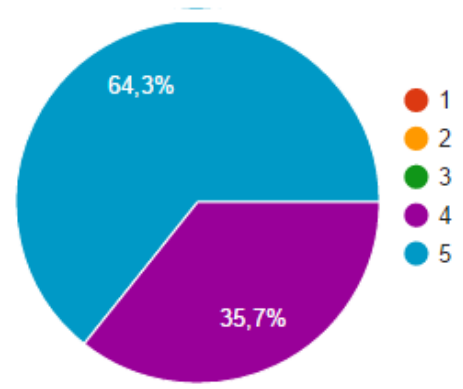

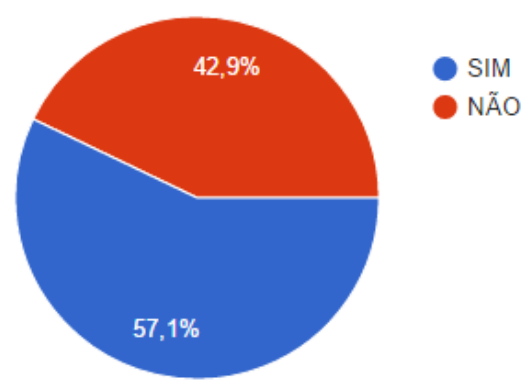

Figura 6. Questões 3 e 4

Nas questões 6 e 7, exibidas na figura 7, é possível verificar um alto grau de aceitação dos usuários com a plataforma de robótica. Em ambas as questões, 100\% dos usuários mostraram um provável interesse em vir a utilizar novamente a plataforma de robótica, bem como, em divulgar a mesma a outras pessoas. Esse interesse dos usuários ficou ainda mais evidente na última questão Dicas e Sugestões, onde alguns comentários 
VI Congresso Brasileiro de Informática na Educação (CBIE 2017)

Anais do XXVIII Simpósio Brasileiro de Informática na Educação (SBIE 2017)

classificaram a plataforma como: Viciante; De grande entretenimento; Divertida e Desafiadora.

Além dos comentários positivos, na última pergunta, várias dicas e sugestões foram propostas pelos usuários. Destacam-se a seguir as principais e que, muito provavelmente, serão avaliadas em futuras melhorias na plataforma: A possibilidade dos comandos manterem-se salvos na tela principal, quando o usuário clicar no ícone histórico para visualizar a execução real do robô, não precisando assim, reescrever todos os comandos novamente; A possibilidade da inserção do último vídeo gerado pelo usuário, na tela principal; $A$ inserção de avisos mais chamativos, quando o usuário coloca um comando que extrapola os limites; Uso de indicadores na interface web que indiquem ao usuário, se o robô está ligado ou não.

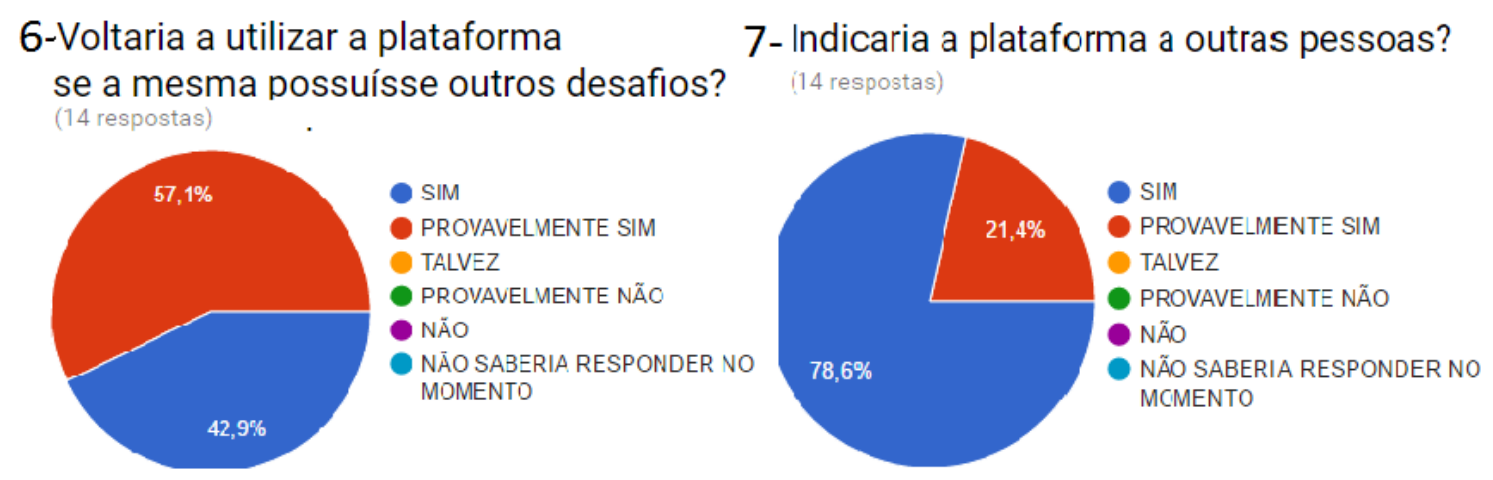

Figura 7. Questões 6 e 7

\section{Conclusão}

Após o término do trabalho foi possível concluir que a plataforma interativa de aprendizagem usando a robótica remota pode ser considerada como uma solução de baixo custo na busca pelo pensamento computacional, por meio da robótica educativa e mais precisamente da programação de robôs. Outro ponto a se destacar é a contribuição para um despertar de interesses dos estudantes a no futuro seguirem carreiras nas áreas correlatas a robótica, cada vez mais carente por profissionais.

Acredita-se que graças à abstração das dificuldades existentes na montagem do dispositivo, como a necessidade de conhecimentos prévios em mecânica e eletrônica, bem como a exclusão da necessidade de adquirir equipamentos robóticos, esse trabalho irá contribuir na ampliação do uso de programação de robôs na educação básica, em especial em situações onde não há condições suficientes de se desenvolver tais atividades.

Por meio dos testes, verificou-se que a plataforma se apresenta como desafiadora aos olhos dos aprendizes, provocando nos mesmos um sentimento de competição, divertimento e motivação para a realização dos desafios. Elementos que atuam como potencializadores no aprendizado, já que propiciam um interesse e envolvimento natural dos estudantes. Essa atração é provocada especialmente pelo fato do usuário vislumbrar sua programação em um robô real, o que pode ser considerado um diferencial se comparado com simuladores robóticos, que apresentam uma imagem gerada por computação gráfica, as quais por vezes não proporcionam a quem estiver programando, 
VI Congresso Brasileiro de Informática na Educação (CBIE 2017)

Anais do XXVIII Simpósio Brasileiro de Informática na Educação (SBIE 2017)

uma sensação de estar no controle de um mecanismo robótico, mesmo que essas repliquem exatamente o funcionamento de um robô.

Também através dos testes, verificou-se a necessidade de algumas modificações no projeto. Dessa forma, como trabalho futuro prevê-se a ampliação da plataforma, com a adição de novas arenas munidas de novos desafios com diferentes níveis de complexidade. Outras funcionalidades a serem implementadas é o desenvolvimento de um aplicativo para uma melhor experiência em dispositivos móveis, bem como, a inserção de sensores e atuadores que juntamente com o front-end serão responsáveis por exibir ao usuário se ele cumpriu os desafios propostos.

As olimpíadas de robótica educativa podem ser consideradas uma oportunidade desafiadora de provocar no estudante a busca pelo pensamento computacional, dessa forma, outra possibilidade de trabalho futuro é o desenvolvimento de arenas voltadas exclusivamente para essas competições, assim como, sistemas de agendamento que possibilitem o uso exclusivo da plataforma no momento da realização das provas, abrindo ainda, o espaço para que a transmissão de vídeo seja realizada em tempo real.

\section{Referências}

Barr, V., Stephenson, C. Bringing computational thinking to k-12: what is involved and what is the role of the computer science education community? ACM Inroads. V. 2. no. 1. p. 48-54. Mar., 2011.

Bezerra, R. e Almada, M. (2015). "Construindo um robô metareciclado: uma proposição de convergência entre robótica educacional e educação socioambiental", Em Anais do XXI Workshop de Informática na Escola (WIE 2015), Maceió-AL, Brasil.

Bouteille, D., Bouteille, N., Chantreuil, S., et al. Les Automatismes Programables. Toulouse, 1997.

Cruz, Marcia K, HAETINGERL, Werner, HORN, Fabiano, CARVALHO, Douglas V. e ARAUJO, Gustavo H. (2009) "Controle de Kit de Robótica através de Laboratório Remoto pela Internet: Uma Aplicação para a Formação Docente e para a Educação Básica", Anais do XX SBIE, Florianópolis.

d'Abreu, J., Ramos, J., Mirisola L., Bernardi, N. Robótica Educativa/Pedagógica na Era Digital. In: II Congresso Internacional TIC e Educação, 2012, Lisboa. Atas do II Congresso Internacional TIC e Educação. Lisboa: Instituto de Educação da Universidade de Lisboa, 2012.

Graig, John J. (2012). Robótica. 3ed. Pearson, 2012. p.192-219.

Kulich, M. Chudoba, J. Kosnar, K. Krajnik, T. Faigl, J. and Preucil, L.. SyRoTek Distance Teaching of Mobile Robotics. IEEE Trans. on Educ. February 2013. IEEE Press. Piscataway, NJ, USA. 2013.

Papert, Seymour; Valente, Jose Armando; BITELMAN, Beatriz. Logo: computadores e educação. Brasiliense, 1980.

Wing, J. M. (2006). "Computational thinking”. Communications of the ACM, Vol. 49, no 3. p.33-35.

Zapata, Nibaldo; Novales, Miguel; Guzmán, J. La robótica educativa como herramienta de apoyo pedagógico. Concepción: Universidad de Concepción, 2004. 